\title{
MMP expression and abnormal lung permeability are important determinants of outcome in IPF
}

\author{
S. McKeown*, A.G. Richter", C. O’Kane*, D.F. McAuley* and D.R. Thickett ${ }^{\#}$
}

ABSTRACT: Matrix metalloproteinases (MMPs) degrade all of the extracellular matrix components of the intersititium and may play a role in abnormal alveolar permeability, which is a feature of idiopathic pulmonary fibrosis (IPF). The aims of the present study were to evaluate MMP protein levels in patients with IPF and determine any relationship to treatment and markers of permeability.

In total, 20 patients with IPF and eight normal controls underwent bronchoalveolar lavage. MMP, tissue inhibitor of metalloproteinase, and vascular endothelial growth factor (VEGF) levels were related to clinical outcome and protein permeability index.

MMP-3, -7, -8 and -9 were elevated in IPF lavage fluid and levels remained high despite treatment. Levels of MMP-3, -7, -8 and -9, VEGF and protein permeability index were higher in those who died early during follow-up. VEGF, and MMP-8 and -9 levels were higher in those with a rapidly declining lung function over $1 \mathrm{yr}$. Levels of MMP-3, -7, -8 and -9 correlated with an increased permeability index.

Matrix metalloproteinase levels were elevated in idiopathic pulmonary fibrosis patients and were not modulated by current standard treatment. Matrix metalloproteinase production through an interaction with the known vascular permogen, vascular endothelial growth factor, was potentially associated with abnormal capillary permeability and may have potentiated the neoangiogenesis seen in idiopathic pulmonary fibrosis. The changes were greatest in those who died or progressed during follow-up, suggesting that drugs targeting vascular endothelial growth factor or matrix metalloproteinase activity warrant assessment as novel therapy for idiopathic pulmonary fibrosis.

KEYWORDS: Idiopathic pulmonary fibrosis, matrix metalloproteinase, vascular endothelial growth factor

diopathic pulmonary fibrosis (IPF) is a progressive lung disease of unknown aetiology [1]. Current theories speculate that IPF results from abnormal wound healing in response to multiple microscopic sites of alveolar epithelial cell (AEC) injury and activation. Microscopic injury is associated with the formation of fibroblast/myofibroblast foci, epithelial cell dropout and the evolution of fibrosis. Disruption of the alveolar epithelium, altered AEC phenotypes, AEC loss and failure of epithelial repair are all distinctive features of IPF [2].

In addition to myofibroblast foci formation and epithelial cell injury, there is variable evidence of inflammation as evidenced by increased macrophage and neutrophil counts [3], intra-alveolar coagulapathy [4] and the formation of new blood vessels in the IPF lung. Abnormal angiogenesis has further been linked to the development of fibrotic disorders of the lung [5]. Together, these changes result in an increase in the permeability of the alveolar capillary barrier, which can be detected clinically by increased DTPA clearance [6].

Currently, the molecular determinants of the abnormal angiogenesis and increased permeability are unclear as studies are somewhat conflicting. Some studies suggest that the proangiogenic ELR+ cytokines, such as interleukin-8 or induced protein-10, promote neo-angiogenesis [7]. Other studies suggest that anti-angiogenic peptides such as pigment epithelium-derived factor are elevated, whereas pro-angiogenic peptides such as vascular endothelial growth factor (VEGF) may be reduced [5]. To further complicate the situation, it appears that expression of these peptides in lung biopsies may be

\section{AFFILIATIONS}

*Respiratory Medicine Research Group, The Queen's University of Belfast, Belfast, and

\#Lung Injury and Fibrosis Treatment Programme, Dept of Medical Sciences, Medical School, University of Birmingham, Birmingham, UK.

CORRESPONDENCE

D.R. Thickett

c/o Lung Investigation Unit 1st floor Nuffield House Birmingham, B15 2TH UK

Fax: 441216272012

E-mail: d.thickett@bham.ac.uk

Received:

April 212008

Accepted after revision:

September 152008

SUPPORT STATEMENT

D.R. Thickett and A.G. Richter were funded by the Wellcome Trust.

C. O'Kane is a National Institute for Health Research clinician scientist.

STATEMENT OF INTEREST

A statement of interest for

D.R. Thickett can be found at

www.erj.ersjournals.com/misc/

statements.shtml

European Respiratory Journal Print ISSN 0903-1936 Online ISSN 1399-3003 
heterogenous; for example, VEGF expression may be reduced within fibroblastic foci [5].

The formation of new blood vessels requires coordinated regulation of matrix proteolysis and endothelial cell migration. Matrix metalloproteinases (MMPs) are essential for extracellular matrix (ECM) remodelling, wound healing and angiogenesis, and have been implicated in the pathogenesis of IPF [8]. Several studies have demonstrated elevated levels of MMP-1, -8 and -9 , which occur in conjunction with alterations in the levels of their soluble inhibitors, tissue inhibitor of metalloproteinases (TIMP)-1 and -2, in IPF. MMP-7 expression is elevated in both human IPF and murine models of fibrosis, whilst MMP-7 knockout mice have attenuated fibrotic reactions $[9,10]$.

Together, the MMPs have the capability of degrading all the collagenous contents of the intersititium and may therefore play a role in abnormal alveolar permeability. The fact that VEGF, which is a known potent inducer of capillary permeability [11], acts in part via actions upon MMP production further supports a role for MMP expression in abnormal vascular permeability in IPF [12, 13].

The aims of the present study were to systematically evaluate the levels of MMP and TIMP protein in patients with IPF, and to determine the relationship of MMP levels with cellular inflammation, bronchoalveolar lavage fluid (BALF) protein permeability index and VEGF levels. In addition, the present study also assessed whether MMP levels are influenced by standard treatment and relate to survival or decline in lung function in IPF patients.

\section{METHODS}

\section{Subjects}

In total, 20 patients with IPF diagnosed according to current American Thoracic Society (ATS) criteria were recruited from the specialist Interstitial Lung Disease clinic at the University Hospital Birmingham (Birmingham, UK). Diagnosis was supported by open lung biopsy in five cases, histology post lung transplant in one case and high-resolution computed tomography evidence in all cases. Where open lung biopsy was performed, tissue was obtained from at least two sites, the upper and lower lobes of the same lung. Baseline bronchoscopy was performed during the investigation stage after referral, before the start of definitive treatment. Eight healthy individuals free from respiratory disease were recruited as normal controls. The study was approved by the local ethical committee and participants gave written informed consent.

\section{Measurements}

Patients underwent bronchoscopy and bronchoalveolar lavage (BAL) as described previously [14]. TIMP-1, TIMP-2 and VEGF were measured in BALF using ELISA kits (R\&D Systems, Abingdon, UK). BALF MMP-1, -2, -3, -7, -8, -9, -12 and -13 were measured using Luminex array (R\&D Systems). Luminex array values for normal MMP levels have been included in an as-yet unpublished study on acute respiratory distress syndrome (ARDS; C. O'Kane, personal communication). IPF MMP-3 levels have been quoted in a further unpublished study concerning endostatin cleavage (A.G. Richter, personal communication). Protein was measured using the Bio-Rad DC Protein Assay Kit II (Bio-Rad Laboratories, Hemel Hempstead, UK). The protein permeability index (PPI) was calculated as the ratio of BALF to plasma protein, as described previously [15].

\section{Gelatin zymography}

Gelatin zymography was carried out as previously described [16]. In brief, BALF was diluted $1 / 10$, and $20-\mu \mathrm{L}$ aliquots were mixed with $5 \mu \mathrm{L}$ loading buffer $(0.25 \mathrm{M}$ Tris $\mathrm{pH} 6.8,50 \%$ glycerol, $5 \%$ SDS, bromophenol blue) and were run on $11 \%$ acrylamide gels impregnated with $0.1 \%$ gelatin at $180 \mathrm{~V}$ for $3.5 \mathrm{~h}$ (buffer $25 \mathrm{mM}$ Tris, $190 \mathrm{mM}$ glycine, $0.1 \%$ SDS). After incubation in $2.5 \%$ Triton $\mathrm{X}$ for $1 \mathrm{~h}$ with agitation and two brief washes in collagenase buffer (55 mM Tris base, $200 \mathrm{mM}$ sodium chloride, $5 \mathrm{mM}$ calcium chloride, $0.02 \%$ Brij, $\mathrm{pH} 7.6$ ), gels were incubated for $16 \mathrm{~h}$ in fresh collagenase buffer at $37^{\circ} \mathrm{C}$. Gelatinolytic activity was detected by a single step stain/ de-stain method using $0.02 \%$ Coomasie blue in $1 / 3 / 6$ acetic acid/methanol/water. All experimental samples were run in parallel with $2 \mathrm{ng}$ recombinant MMP-9 (Oncogene, Cambridge, UK) to standardise between gels.

\section{MMP-9 activity assay}

BALF was diluted $1 / 25$ or $1 / 50$ and analysed using the MMP-9 fluorokine activity assay (R\&D Systems) according to the manufacturer's instructions. A standard curve of purified MMP-9 was run on the same plates (and pro-forms of MMP-9 standard were activated by 4-aminophenylmercuric acetate (APMA) for $2 \mathrm{~h}$ before the addition of the fluorogenic substrate) to allow quantification. The minimal detectable concentration of MMP-9 using this assay is reported as $5 \mathrm{pg} \cdot \mathrm{mL}^{-1}$ (manufacturer's data). This assay takes into account the effect of TIMPs in the sample and gives a measure of net MMP-9 activity.

\section{Pulmonary function testing}

Forced vital capacity (FVC) was measured using the Jaeger Compact system (Viasys Healthcare, Basingstoke, UK). Total lung diffusing capacity for carbon monoxide $(T \mathrm{~L}, \mathrm{CO})$ was measured using a single-breath technique (Jaeger Compact system). Results were expressed as \% of predicted values. Where possible, sequential lung function was obtained 3 monthly as part of clinical follow-up. Rapid lung decline was defined as a consistent reduction $(>10 \%)$ in FVC, total lung capacity or TL,CO 1 yr after presentation [1].

\section{Statistics}

IPF BALF protein data were non-parametric and are thus presented as median (interquartile range $(\mathrm{IQR})$ ). Betweengroup comparisons were performed using the Mann-Whitney U-test. A p-value of $\leqslant 0.05$ for all data was considered significant. Correlations were made using the Pearson's test after log transformation of non-parametric data. The present study was considered hypothesis-generating so a power calculation was not performed.

\section{RESULTS \\ Demographics}

In total, 20 patients with IPF and eight healthy controls were recruited. A summary of patient characteristics is shown in table 1 . Eight patients agreed to a sequential BAL 3-6 months after starting treatment with prednisolone $0.5 \mathrm{mg} \cdot \mathrm{kg}^{-1}$ and azathioprine $1-1.5 \mathrm{mg} \cdot \mathrm{kg}^{-1}$ with or without $N$-acetylcysteine 


\begin{tabular}{|c|c|c|}
\hline & IPF & Normal controls \\
\hline Patients & 20 & 8 \\
\hline Age yrs & $70(52-86)$ & $45(34-58)^{\circ}$ \\
\hline Males & 16 & 4 \\
\hline \multicolumn{3}{|l|}{ Smoking status } \\
\hline Current smoker & 5 & 3 \\
\hline Ex-smoker & 12 & 3 \\
\hline Never-smoker & 3 & 2 \\
\hline Pack-yrs & $30 \pm 20$ & $21 \pm 16$ \\
\hline FVC \% pred & $73 \pm 19.7$ & $\mathrm{n} / \mathrm{a}$ \\
\hline$T L, C O \%$ pred $^{\#}$ & $49 \pm 14.4$ & $\mathrm{n} / \mathrm{a}$ \\
\hline TLC \% pred ${ }^{\#}$ & $75 \pm 16.3$ & $\mathrm{n} / \mathrm{a}$ \\
\hline Baseline oxygen saturation \% & $94 \pm 3$ & $97 \pm 1$ \\
\hline \multicolumn{3}{|c|}{$\begin{array}{l}\text { Data are presented as } n \text {, value (range) or mean } \pm \text { SD. IPF: idiopathic pulmonary } \\
\text { fibrosis; FVC: forced vital capacity; \% pred: \% predicted; } T L, C O \text { : transfer factor } \\
\text { of the lung for carbon monoxide; TLC: total lung capacity; } n / a \text { : not applicable. } \\
\# \text { : expressed as percentage of normal. }{ }^{\circ}: p=0.01 \text {. }\end{array}$} \\
\hline
\end{tabular}

$600 \mathrm{mg}$ three times daily. Patients had to be free from clinical suggestion of pulmonary infection in the 4 weeks prior to bronchoscopy.

Of the 20 IPF patients enrolled in the present study, 12 died during the 3-yr period of follow-up. The cause of death was deterioration of lung function causing respiratory failure $(n=5)$, lung carcinoma $(n=3)$, pneumonic infection $(n=2)$, pulmonary embolus $(n=1)$ and myocardial infarction $(n=1)$. One patient underwent lung transplantation during the followup period. Median time to death was 18 months from time of first bronchoscopy.

\section{Elevated BALF macrophage and neutrophil counts in patients with IPF}

IPF BALF cell count (median 1,260,000 cells $\cdot \mathrm{mL}^{-1}$ (IQR 560,000$3,220,000$ cells $\left.\cdot \mathrm{mL}^{-1}\right)$ ) was significantly increased compared with normal BALF cell count $\left(412,000\right.$ cells $\cdot \mathrm{mL}^{-1} \quad(253,000-470,000$ cells $\left.\left.\cdot \mathrm{mL}^{-1}\right) ; \mathrm{p}=0.0034\right)$. A significantly elevated total alveolar macrophage (AM) count was noted (IPF: 1,030,000 AMs $\cdot \mathrm{mL}^{-1}$ BALF (446,000-2,740,000 AMs $\cdot \mathrm{mL}^{-1}$ BALF); normal: 391,000 $\left.\mathrm{AMs} \cdot \mathrm{mL}^{-1}\left(245,000-450,000 \mathrm{AMs} \cdot \mathrm{mL}^{-1}\right) ; \mathrm{p}=0.0051\right)$. BALF \% macrophage count was reduced (IPF: \% AM 88.3 (73.2-94.1); normal BAL: \% AM 96 (95.5-97.7); $\mathrm{p}=0.031)$.

There was an increase in IPF BALF total and \% neutrophil count compared with normal BALF counts. Total IPF neutrophil count was 120,000 cells $\cdot \mathrm{mL}^{-1}\left(56,500-279,000\right.$ cells $\left.\cdot \mathrm{mL}^{-1}\right)$ and normal total neutrophil count was 400 cells $\cdot \mathrm{mL}^{-1}\left(52.5-956\right.$ cells $\left.\cdot \mathrm{mL}^{-1}\right)$; $\mathrm{p}=0.0373$. IPF BALF \% neutrophil count was $11.7 \%(5.9-26.8 \%)$ and normal was $2 \%(0.75-2.75 \%) ; p=0.016$. There was an increase in \% neutrophils (but not total neutrophils or macrophages) in patients who died during the follow-up phase (in those who died: $25.0 \%$ neutrophils (13-62\% neutrophils); in those who survived: $7.9 \%$ neutrophils; $p=0.05$ ), as has recently been reported [3]. There was no significant difference in BALF lymphocyte or eosinophil count between normal and IPF BALF in the cohort of the present study.

\section{Elevated MMPs in patients with IPF}

MMP-7, -8 and -9 represent the majority of MMP protein in IPF BALF (fig. 1). MMP-2, $-3,-7,-8$ and -9 levels were significantly elevated compared with those in normal control patients (table 2). In the eight patients who underwent sequential bronchoscopy after treatment, levels of MMP-2, -3, -7, -8 and -9 remained elevated (table 2). BALF levels of MMP-12 and -13 were largely undetectable in both normal and IPF BALF, and were not further demonstrated. MMP levels did not correlate with age, sex, smoking status or pack-yr history (data not shown).

\section{Elevated BALF MMP levels in those who have rapid progression of lung function $1 \mathrm{yr}$ after presentation}

BALF levels of MMP- 3, $-7,-8$ and -9 were elevated in those patients who had a rapid decline in lung function $(n=8)$ compared with non-rapid progressing cases $(n=12)$. However, only the differences between MMP-8 and -9 were significant (table 3). There were no important relationships of IPF BALF MMP-1, $-2,-8,-12$ or -13 with FVC, TL,CO or transfer coefficient of the lung for carbon monoxide. BALF MMP-7 correlated weakly with $T \mathrm{~L}, \mathrm{CO}(\mathrm{r}=0.28, \mathrm{p}=0.008)$ and MMP-3 correlated with FVC $(r=0.20, p=0.048)$.

\section{Elevated MMP levels in those who died during follow-up}

The present cohort of patients had a mortality level of $40 \%$ during the 3 yrs of follow-up. BALF levels of MMP-3, -8 and -9 were elevated in those who subsequently died during the follow-up phase (table 4). MMP levels in those who died did not predict the time to death.

\section{Elevated BALF TIMP-1 and -2 in patients with IPF}

TIMP-1 and -2 levels were elevated in first and sequential BALF compared to normal. Median normal BALF TIMP-1 was $505 \mathrm{pg} \cdot \mathrm{mL}^{-1} \quad$ (IQR $\left.290-1,062 \mathrm{pg} \cdot \mathrm{mL}^{-1}\right)$ versus $7,343 \mathrm{pg} \cdot \mathrm{mL}^{-1}$ $\left(1,830-18,668 \mathrm{pg} \cdot \mathrm{mL}^{-1}\right)$ for IPF BALF TIMP-1 $(p=0.0044)$. BALF TIMP-1 remained elevated in those IPF patients who had treatment $\left(\mathrm{n}=8 ; 9,725 \mathrm{pg} \cdot \mathrm{mL}^{-1} \quad\left(2,500-20,230 \mathrm{pg} \cdot \mathrm{mL}^{-1}\right)\right.$; $\mathrm{p}=0.0022$ ) compared to normal (fig. 2).

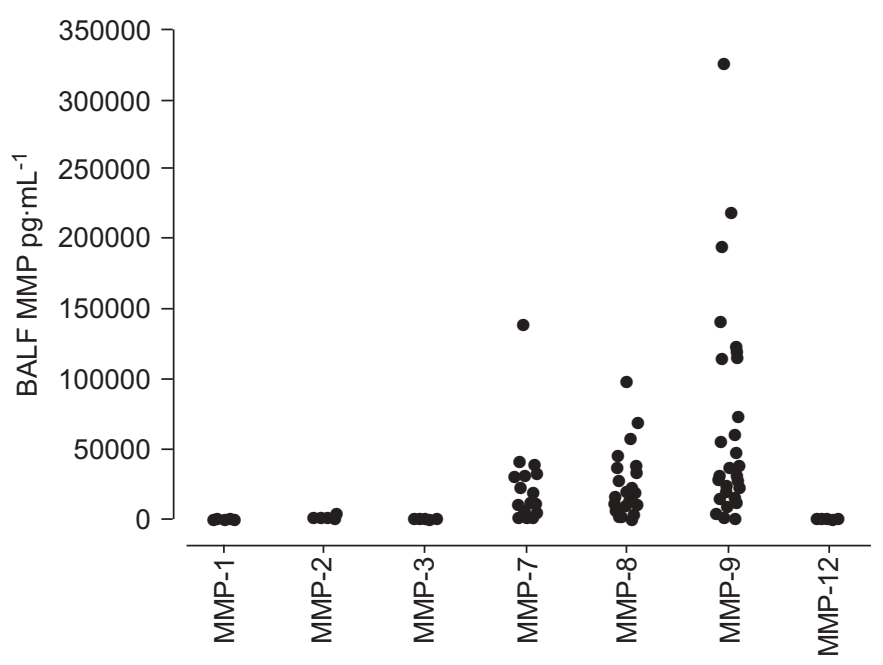

FIGURE 1. Bronchoalveolar lavage fluid (BALF) matrix metalloproteinase (MMP) levels expressed as a scatter plot. BALF data were combined from baseline and follow-up bronchoscopy $(n=28)$. The scatter plot demonstrates that the majority of BALF MMP protein is MMP-7, -8 and -9 
TABLE 2 Bronchoalveolar lavage (BAL) matrix metalloproteinase (MMP) levels in normal controls versus baseline BAL (BAL1) and follow-up bronchoscopy (BAL2) in idiopathic pulmonary fibrosis (IPF) patients

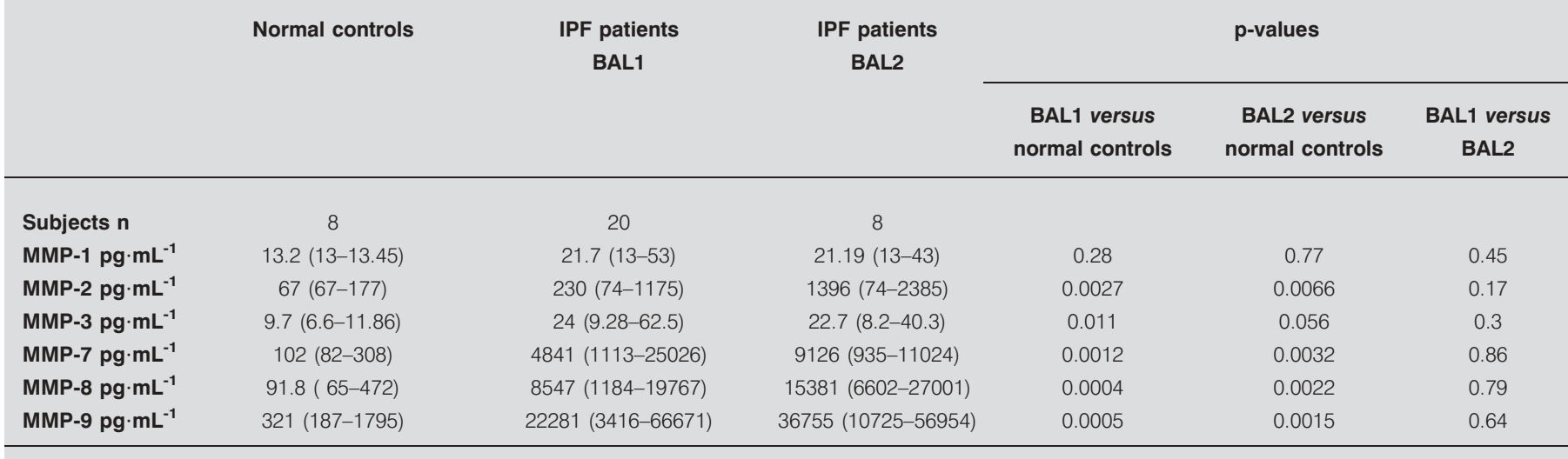

Data are presented as median (interquartile range), unless otherwise stated.

TABLE 3 Matrix metalloproteinase (MMP) levels in patients whose lung function rapidly declined over $1 \mathrm{yr}$ compared with those in whom there was no significant decline

\begin{tabular}{|c|c|c|c|}
\hline & Rapid lung function decline & Non-rapid lung function decline & p-value \\
\hline Subjects $\mathrm{n}$ & 8 & 12 & \\
\hline MMP-1 pg $\cdot \mathrm{mL}^{-1}$ & $22(13-86)$ & $13(13-18)$ & 0.56 \\
\hline MMP-3 pg $\cdot \mathrm{mL}^{-1}$ & $59.6(23.4-92)$ & $20.5(4.3-27.8)$ & 0.058 \\
\hline MMP-7 pg $\cdot \mathrm{mL}^{-1}$ & 11095 (3505-32552) & $4822(260-17312)$ & 0.29 \\
\hline MMP-8 $\mathrm{pg} \cdot \mathrm{mL}^{-1}$ & 26427 (11190-38160) & $2533(570-11431)$ & 0.028 \\
\hline
\end{tabular}

Data are presented as median (interquartile range), unless otherwise stated. Rapid lung decline was defined as a consistent reduction $(>10 \%)$ in forced vital capacity, total lung capacity or transfer factor of the lung for carbon monoxide $1 \mathrm{yr}$ after presentation.

TABLE 4 Elevated bronchoalveolar lavage (BAL) fluid matrix metalloproteinase (MMP) and protein permeability in patients who died early during follow-up

\begin{tabular}{|c|c|c|c|}
\hline & Died & Survived & p-value \\
\hline Subjects $\mathrm{n}$ & 8 & 12 & \\
\hline MMP-1 pg $\cdot \mathrm{mL}^{-1}$ & $13(13-56)$ & $16.6(13-76.8)$ & 0.79 \\
\hline MMP-2 pg $\cdot \mathrm{mL}^{-1}$ & $74(91-813)$ & $74(74-1092)$ & 0.75 \\
\hline MMP-3 pg $\cdot \mathrm{mL}^{-1}$ & $72(28-91)$ & $8(3-28.5)$ & 0.0081 \\
\hline MMP-7 pg $\cdot \mathrm{mL}^{-1}$ & 10012 (4650-30399) & $3187(88-10105)$ & 0.16 \\
\hline MMP-12 pg $\cdot \mathrm{mL}^{-1}$ & 18 & 18 & 0.96 \\
\hline BAL protein $\mathrm{mg} \cdot \mathrm{mL}^{-1}$ & 0.38 & 0.23 & 0.3415 \\
\hline PPI & $0.01594(0.008-0.044)$ & $0.00434(0.0033-0.0482)$ & 0.04 \\
\hline Plasma protein $\mathrm{mg} \cdot \mathrm{mL}^{-1}$ & 92 & 126 & 0.458 \\
\hline TIMP-1 pg $\cdot \mathrm{mL}^{-1}$ & 15185 (7674-23593) & $2245(1070-7063)$ & 0.01 \\
\hline TIMP-2 pg $\cdot \mathrm{mL}^{-1}$ & $1448(765-2102)$ & $488(365-1693)$ & 0.02 \\
\hline
\end{tabular}

Data are presented as median (interquartile range) or median, unless otherwise stated. PPI: protein permeability index; TIMP: tissue inhibitor of metalloproteinase 

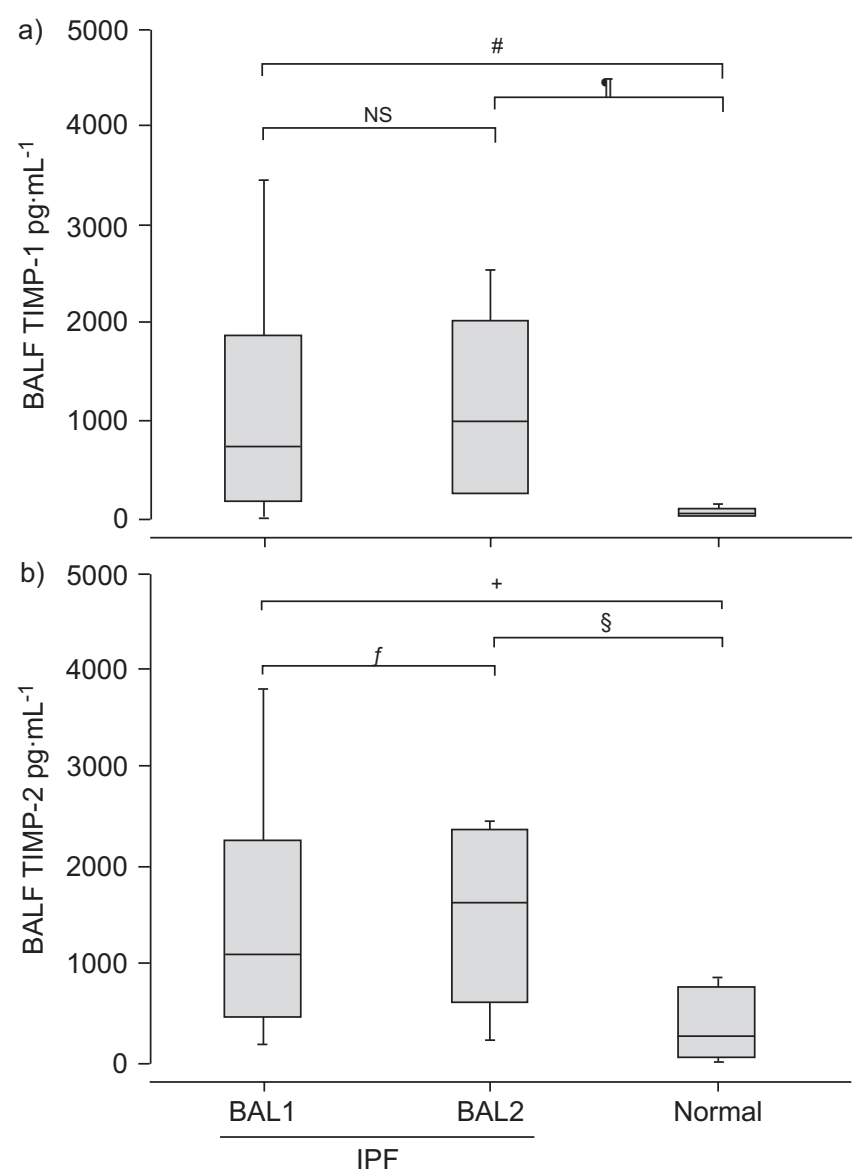

FIGURE 2. Boxplots of bronchoalveolar lavage fluid (BALF) levels of a) tissue inhibitor of metalloproteinase (TIMP)-1 and b) TIMP-2 are persistently elevated in patients with idiopathic pulmonary fibrosis (IPF), both at baseline (BAL1) and at follow-up bronchoscopy (BAL2). The horizontal bars intersecting the boxes represent the median and the boxes represent the interquartile range; whiskers show the minimum-maximum range. Ns: nonsignificant. ${ }^{\#}: p=0.0044 ;{ }^{\circ}: p=0.0022$; $+: p=0.0046 ;{ }^{\varsigma}: p=0.024 ;{ }^{f}: p=0.49$.

Initial IPF BALF TIMP-2 levels $\left(898 \mathrm{pg} \cdot \mathrm{mL}^{-1}\left(460-1,836 \mathrm{pg} \cdot \mathrm{mL}^{-1}\right)\right.$; $\mathrm{p}=0.0046)$ and IPF repeat BALF TIMP-2 levels $\left(1,623 \mathrm{pg} \cdot \mathrm{mL}^{-1}\right.$ $\left.\left(606-2,296 \mathrm{pg} \cdot \mathrm{mL}^{-1}\right) ; \mathrm{p}=0.0022\right)$ were elevated compared to normal $\left(276 \mathrm{pg} \cdot \mathrm{mL}^{-1}\left(43-764 \mathrm{pg} \cdot \mathrm{mL}^{-1}\right)\right.$; fig. $\left.2 \mathrm{~b}\right)$. There were no relationships between TIMP-1 or -2 levels and static lung function at diagnosis. BALF TIMP-1 and -2 levels were elevated in those who died during follow-up compared to survivors (table 4).

\section{Molar ratios of MMP: altered TIMP in IPF}

Calculation of the MMP/TIMP-1 molar ratio suggested that there was no difference between MMP-1 and -2 and normal. MMP-3 molar ratio was significantly reduced (IPF 0.00304 versus normal $0.02 ; \mathrm{p}=0.0066)$. In contrast, molar ratios were increased for MMP-7 (IPF 0.89 versus normal 0.25; $\mathrm{p}=0.0374$ ), MMP-8 (IPF 0.417 versus normal $0.092 ; \mathrm{p}=0.0078$ ) and MMP-9 (IPF 0.973 versus normal $0.171 ; \mathrm{p}=0.018)$. MMP/TIMP-2 ratios were not elevated compared to normal for MMP-1, -2 and -3 , but were significantly elevated for MMP-7, -8 and -9 (data not shown).

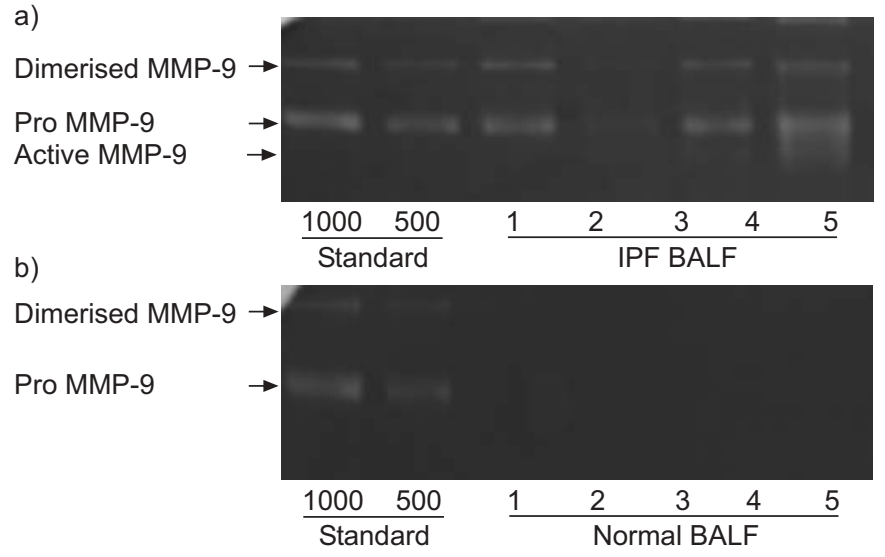

FIGURE 3. Representative gels (using zymography) demonstrating increased matrix metalloproteinase (MMP) activity in a) idiopathic pulmonary fibrosis (IPF) bronchoalveolar lavage fluid (BALF) compared to b) normal.

In order to confirm that protein levels reflected activity, BALF MMP activity assays were performed for MMP-9. MMP-9 was chosen as it is the best validated assay for MMP activity.

\section{Elevated MMP activity in patients with IPF}

Using zymography, MMP-9 was detected in 19 out of 20 patients with IPF and one normal control patient. A representative gel is shown in figure 3. Fluorimetric MMP-9 activity was $23,791 \mathrm{pg} \cdot \mathrm{mL}^{-1}\left(5,145-62,787 \mathrm{pg} \cdot \mathrm{mL}^{-1}\right)$ in IPF BALF compared to those below the detection limit in seven out of eight samples (median allocated value $125 \mathrm{pg} \cdot \mathrm{mL}^{-1} ; \mathrm{p}=0.000$ ). The addition of APMA increased the activity of MMP-9 in IPF BALF from $23,791 \mathrm{pg} \cdot \mathrm{mL}^{-1}$ to $52,529 \mathrm{pg} \cdot \mathrm{mL}^{-1} \quad(11,728-$ $134,631 \mathrm{pg} \cdot \mathrm{mL}^{-1} ; \mathrm{p}=0.14$; fig. 4).

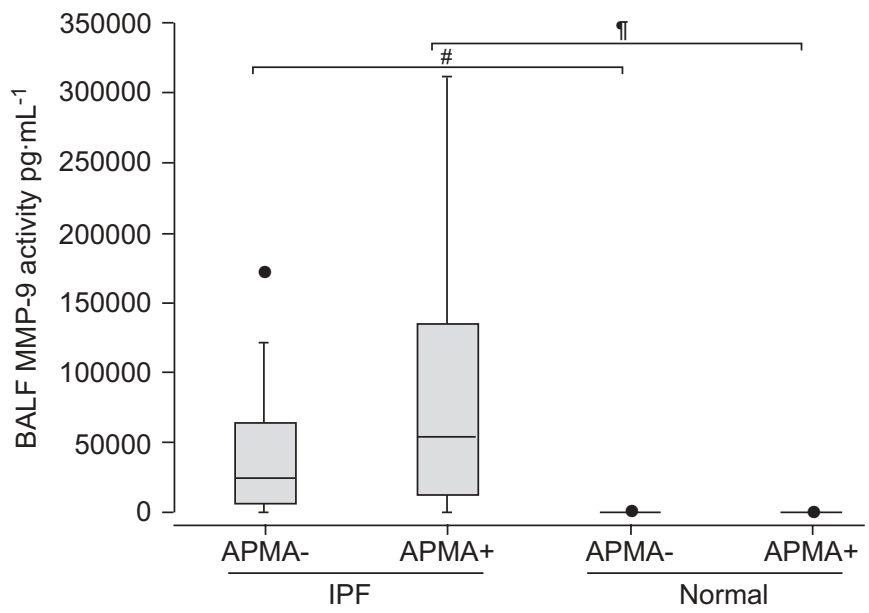

FIGURE 4. Bronchoalveolar lavage fluid (BALF) matrix metalloproteinase (MMP)-9 activity assay. 4-aminophenylmercuric acetate (APMA) maximally activates MMP-9. IPF: idiopathic pulmonary fibrosis. The horizontal bars intersecting the boxes represent the median and the boxes represent the interquartile range; whiskers show the minimum-maximum range. $\bullet$ : individual outliers. +: with APMA activation; -: without APMA activation. ${ }^{*}: p=0.0003 ;{ }^{\circ}: p=0.0001$. 

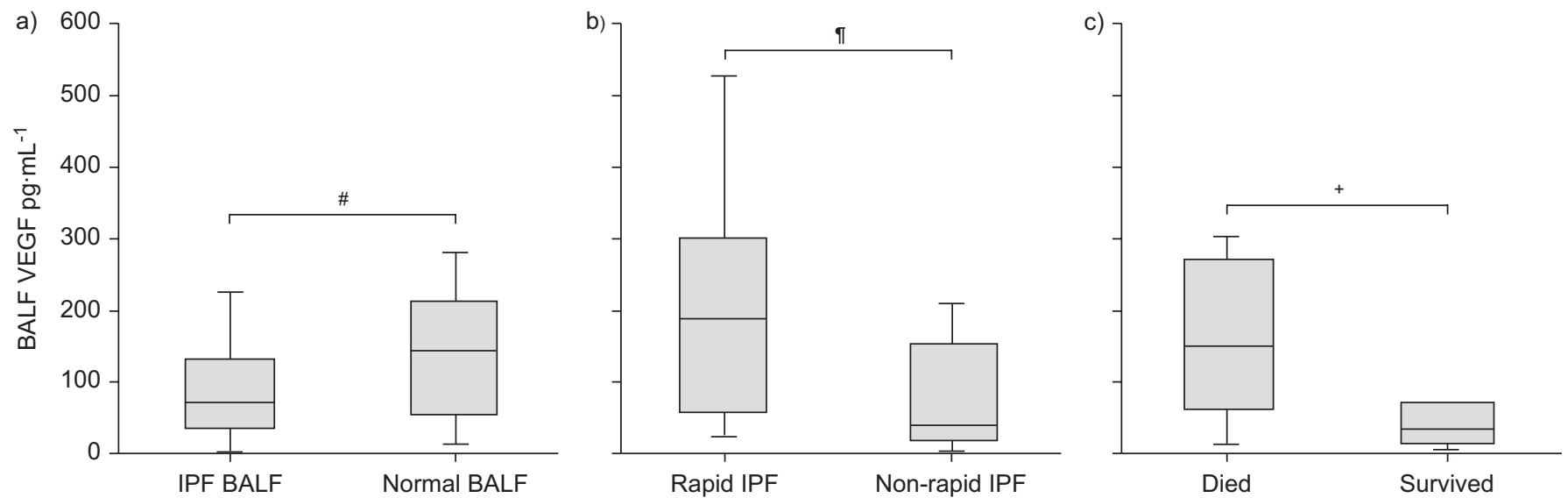

FIGURE 5. Bronchoalveolar lavage fluid (BALF) vascular endothelial growth factor (VEGF) levels in a) normal BALF and idiopathic pulmonary fibrosis (IPF) BALF, b) rapid IPF and non-rapid IPF, and c) IPF subjects who died and subjects who survived. a) BALF VEGF does not differ between normal and IPF patients (all 20 considered at baseline). c) BALF VEGF is greater in IPF patients who died during follow-up rather than survived. The horizontal bars intersecting the boxes represent the median and the boxes represent the interquartile range; whiskers show the minimum-maximum range. ${ }^{*}: p=0.499 ;{ }^{\bullet}: p=0.04 ;{ }^{+}: p=0.03$.

\section{BALF VEGF levels in IPF}

VEGF levels in IPF patients were not significantly different in patients with IPF compared to normal $\left(82 \mathrm{pg} \cdot \mathrm{mL}^{-1}\right.$ (25$222 \mathrm{pg} \cdot \mathrm{mL}^{-1}$ ) versus $140 \mathrm{pg} \cdot \mathrm{mL}^{-1} ; \mathrm{p}=0.499$; fig. 5a). VEGF levels did not correlate with baseline lung function. Initial IPF BALF levels of VEGF correlated significantly with both protein permeability index $(\mathrm{r}=0.51, \mathrm{p}=0.026)$ and with BALF MMP-3 $(\mathrm{r}=0.53, \mathrm{p}=0.003)$, MMP-7 $(\mathrm{r}=0.36, \mathrm{p}=0.02)$, MMP-8 $(\mathrm{r}=0.38$, $\mathrm{p}=0.018)$ and MMP-9 $(\mathrm{r}=0.34, \mathrm{p}=0.029$; data not shown $)$.

Baseline BALF VEGF levels were elevated in patients who had a rapid decline in lung function over the first year of follow-up $\left(188 \mathrm{pg} \cdot \mathrm{mL}^{-1}\left(56-301.7 \mathrm{pg} \cdot \mathrm{mL}^{-1}\right)\right)$ compared to IPF non-progressors (38.4 $\mathrm{pg} \cdot \mathrm{mL}^{-1}\left(16.8-152.1 \mathrm{pg} \cdot \mathrm{mL}^{-1}\right) ; \mathrm{p}=0.04$; fig. $\left.5 \mathrm{~b}\right)$. Baseline BALF VEGF levels were also elevated in patients who died $\left(159 \mathrm{pg} \cdot \mathrm{mL}^{-1}\left(62-272 \mathrm{pg} \cdot \mathrm{mL}^{-1}\right)\right.$ compared to those who survived (34 $\mathrm{pg} \cdot \mathrm{mL}^{-1}\left(13.9-70 \mathrm{pg} \cdot \mathrm{mL}^{-1}\right) ; \mathrm{p}=0.03$; fig. $\left.5 \mathrm{c}\right)$.

\section{Elevated PPI in patients with IPF}

IPF BALF PPI was elevated $(0.00439 \quad(0.000853-0.0148))$ compared to normal (0.00196 (0.000714-0.0026); $\mathrm{p}=0.044$; fig. 6). Levels of PPI were greatest in those who died (0.01594) within the 3 yrs of follow-up ( $p=0.04$; table 4 and fig. 6b). In contrast, neither plasma protein levels nor BALF total protein had any relationship with outcome (table 4). PPI did not differ significantly in those with a rapid decline in lung function (data not shown).

\section{DISCUSSION}

MMPs capable of degrading various components of connective tissue matrices are believed to play a significant role in remodelling after parenchymal damage, resulting in tissue destruction or the induction of repair processes in pulmonary diseases [17]. In the present study, it has been demonstrated that the predominantly elevated MMPs in IPF BALF were 7, 8 and 9. MMP-7 levels have previously been shown to be upregulated in microarray studies and in one lavage study of IPF patients [9, 18]. Another study demonstrated elevated MMP-8 and neutrophil-derived MMP-9 in BALF [8]. A further study by SuGA et al. [19] confirmed increased MMP-9 activity in
IPF, particularly in those with rapid progression. Similar to the present findings, a previous study did not show elevation of MMP-1 but did not confirm the present authors' finding of increased TIMP-1 levels [8].

In previous animal studies, it has been shown that MMP-12 has an important role in the development of lung fibrosis [20]. It is difficult to reconcile these findings with the low/undetectable levels of MMP-12 seen in the present study. It is important to recognise that the tissue levels of MMP-12 do not necessarily reflect BALF levels due to the complex regulation of MMPs by local inhibitors; clearly, further studies are warranted in human disease to elucidate the role of MMP-12 in human lung fibrosis.

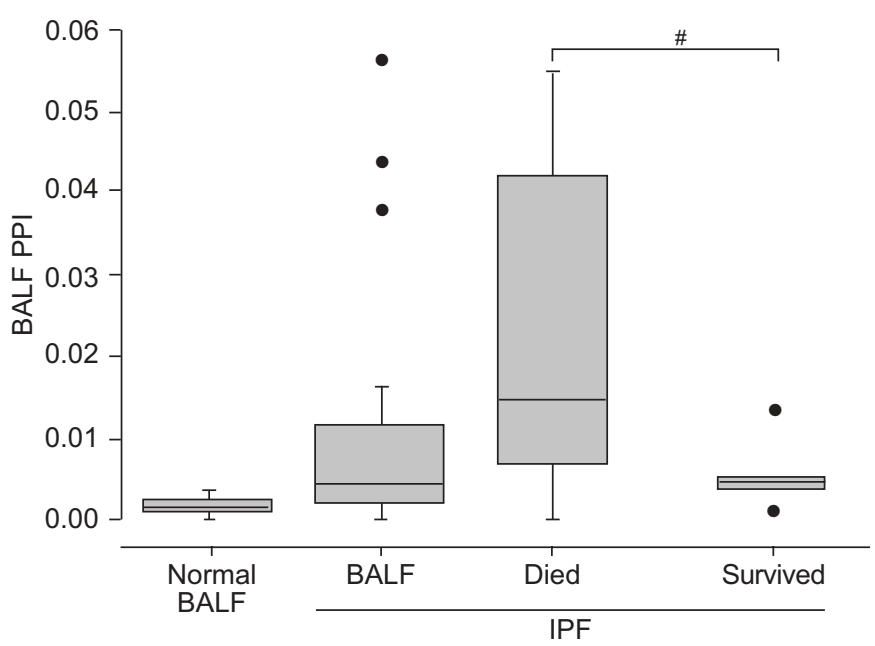

FIGURE 6. Protein permeability index (PPI) in bronchoalveolar lavage fluid (BALF) showed an increase in idiopathic pulmonary fibrosis (IPF) patients compared to normal. IPF patients who died during follow-up showed significantly elevated PPI compared to survivors. The horizontal bars intersecting the boxes represent the median and the boxes represent the interquartile range; whiskers show the minimum-maximum range. $\bullet$ : individual outliers. ${ }^{*}: p=0.04$. 
MMP activity is regulated in part by the activity of TIMPs. Thus, simple BALF MMP immunoreactivity does not necessarily reflect bioactivity. To try and address this, the present authors analysed the protein levels of TIMP-1 and -2 as well as the net BALF activity of MMP-9. The net MMP/TIMP molar ratios were elevated in IPF compared with normal control individuals for MMP-7, -8 and -9 . The activity assay confirmed the increased activity of MMP-9 in the lavage fluid, a finding confirmed by zymography. This would suggest that elevated MMP-9 is bioactive within the lungs of IPF patients.

In the present study, the authors tried to assess the relationship between MMP expression and PPI (ratio of BAL/plasma protein). The PPI has been widely used to assess the integrity of epithelial barrier function in patients with ARDS [15], and as the airway permeability index in patients with asthma [21]. To the present authors' knowledge, no previous studies have assessed its utility in IPF patients. The present authors have demonstrated an increased index compared to normal, which relates to both VEGF and MMP levels, and is elevated in those who die early with IPF. The fact that neither plasma protein nor BALF protein had a relationship with outcome supports the validity of the index in the setting of IPF.

In IPF, it has been recognised that the structural integrity of the alveolar wall depends on the basement membrane and that destruction of the subepithelial basement membrane may precede the development of alveolar fibrosis. A discontinuity of the basement membrane allows greater access for exudative factors and interstitial cells to the alveolar space, potentially promoting further tissue destruction and progressive fibrosis. In the present study, the finding of relationships between MMP levels and the PPI supports a role for MMP-3, $-7,-8$ and -9 directly in the permeability of the alveolar barrier in IPF. The correlation between VEGF and both the PPI and MMPs supports a role for VEGF in this abnormal permeability. VEGF is known to promote both neo-angiogenesis and increase vascular permeability, as well as promote epithelial proliferation and repair [11, 22, 23]. In addition, MMPs can activate matrix bound growth factors such as VEGF, potentially increasing their bioavailability. Clearly, the finding of elevated levels of PPI, MMP-3, -7 and -9, and VEGF in those patients who die or progress early suggests that these changes are of clinical significance.

Current treatment for IPF remains unsatisfactory and there is little evidence that the usual interstitial pneumonia (UIP) pattern on lung biopsy ever regresses with treatment. A recent trial has, however, suggested that treatment with prednisolone, azathioprine and $N$-acetylcysteine slows progression [24]. The present data demonstrate clearly that, in the subgroup of patients who agreed to repeat BAL 3-6 months after such combination drug therapy, this therapy does not have any suppressive activity upon BALF MMP immunoreactivity. This is despite the fact that a previous study suggests that steroid treatment reduces MMP-9 production from IPF patients treated with steroids and azathioprine [25]; however, in that study, patients were not individually studied consecutively pre- and post-treatment.

The present study has several limitations. First, the patient population did not all undergo lung biopsies to prove UIP, although they were well characterised according to international guidelines in a specialist clinic. Furthermore, the difference in age between the IPF patients and the healthy controls may be a confounding factor when comparing MMP levels. To address this, the relationship between age and MMP levels in IPF and normal controls was examined and no correlation was found. Finally, it is important to understand that MMP levels in BALF do not necessarily reflect activity within the interstitium but the present results do confirm findings from previous studies. As BAL only samples the alveolar component of the lung's response to disease, it is likely that the altered production of the other collagenases in sites not sampled by BAL can also contribute to the initiation of collagen remodelling in this disease.

In summary, the present study systematically assessed a range of matrix metalloproteinases known to be important in pulmonary disease, in idiopathic pulmonary fibrosis patients both before and after treatment. Matrix metalloproteinase activity was raised and did not appear to be influenced by treatment. Levels of matrix metalloproteinase correlated with an increased protein permeability index and the known vascular permogen, vascular endothelial growth factor, suggesting that matrix metalloproteinase production is involved in abnormal capillary permeability and potentially the neo-angiogenesis seen in idiopathic pulmonary fibrosis. The fact that these changes were greatest in those who died or progressed during the follow-up phase suggests significant clinical importance. In conclusion, it is suggested that drugs targeting matrix metalloproteinase activity currently in development for chronic obstructive pulmonary disease warrant assessment as novel therapy for idiopathic pulmonary fibrosis.

\section{REFERENCES}

1 American Thoracic Society. Idiopathic pulmonary fibrosis: diagnosis and treatment. International consensus statement. American Thoracic Society (ATS) and the European Respiratory Society (ERS). Am J Respir Crit Care Med 2000; 161: 646-664.

2 Selman M, King TE, Pardo A. Idiopathic pulmonary fibrosis: prevailing and evolving hypotheses about its pathogenesis and implications for therapy. Ann Intern Med 2001; 134: 136-151.

3 Kinder BW, Brown KK, Schwarz MI, Ix JH, Kervitsky A, King TE Jr. Baseline BAL neutrophilia predicts early mortality in idiopathic pulmonary fibrosis. Chest 2008; 133: 226-232.

4 Günther A, Mosavi P, Ruppert C, et al. Enhanced tissue factor pathway activity and fibrin turnover in the alveolar compartment of patients with interstitial lung disease. Thromb Haemost 2000; 83: 853-860.

5 Cosgrove GP, Brown KK, Schiemann WP, et al. Pigment epithelium-derived factor in idiopathic pulmonary fibrosis: a role in aberrant angiogenesis. Am J Respir Crit Care Med 2004; 170: 242-251.

6 Mogulkoc N, Brutsche MH, Bishop PW, et al. Pulmonary (99m)Tc-DTPA aerosol clearance and survival in usual interstitial pneumonia (UIP). Thorax 2001; 56: 916-923.

7 Keane MP, Arenberg DA, Lynch JP 3rd, et al. The CXC chemokines, IL-8 and IP-10, regulate angiogenic activity in 
idiopathic pulmonary fibrosis. J Immunol 1997; 159: 1437-1443.

8 Henry MT, McMahon K, Mackarel AJ, et al. Matrix metalloproteinases and tissue inhibitor of metalloproteinase- 1 in sarcoidosis and IPF. Eur Respir J 2002; 20: 1220-1227.

9 Pardo A, Gibson K, Cisneros J, et al. Up-regulation and profibrotic role of osteopontin in human idiopathic pulmonary fibrosis. PLoS Med 2005; 2: e251.

10 Vuorinen K, Myallärniemi M, Lammi L, et al. Elevated matrilysin levels in bronchoalveolar lavage fluid do not distinguish idiopathic pulmonary fibrosis from other interstitial lung diseases. Apmis 2007; 115: 969-975.

11 Thickett DR, Armstrong L, Christie SJ, Millar AB. Vascular endothelial growth factor may contribute to increased vascular permeability in acute respiratory distress syndrome. Am J Respir Crit Care Med 2001; 164: 1601-1605.

12 Kong D, Li Y, Wang Z, Banerjee S, Sarkar FH. Inhibition of angiogenesis and invasion by 3,3'-diindolylmethane is mediated by the nuclear factor- $\kappa \mathrm{B}$ downstream target genes MMP-9 and UPA that regulated bioavailability of vascular endothelial growth factor in prostate cancer. Cancer Res 2007; 67: 3310-3319.

13 Jin HY, Lee KS, Jin SM, Lee YC. Vascular endothelial growth factor correlates with matrix metalloproteinase-9 in the pleural effusion. Respir Med 2004; 98: 115-122.

14 Thickett DR, Armstrong L, Millar AB. A role for vascular endothelial growth factor in acute and resolving lung injury. Am J Respir Crit Care Med 2002; 166: 1332-1337.

15 Perkins GD, Chatterjie S, McAuley DF, Gao F, Thickett DR. Role of nonbronchoscopic lavage for investigating alveolar inflammation and permeability in acute respiratory distress syndrome. Crit Care Med 2006; 34: 57-64.

16 Elkington PT, Green JA, Emerson JE, et al. Synergistic upregulation of epithelial cell matrix metalloproteinase-9 secretion in tuberculosis. Am J Respir Cell Mol Biol 2007 37: 431-437.

17 Tang W, Guo Q, Qu X, et al. KL-6 mucin is a useful immunohistochemical marker for cholangiocarcinoma. Oncol Rep 2007; 17: 737-741.

18 Vuorinen K, Gao F, Oury TD, Kinnula VL, Myllärniemi M. Imatinib mesylate inhibits fibrogenesis in asbestos-induced interstitial pneumonia. Exp Lung Res 2007; 33: 357-373.

19 Suga $M$, Iyonaga $K$, Okamoto $\mathrm{T}$, et al. Characteristic elevation of matrix metalloproteinase activity in idiopathic interstitial pneumonias. Am J Respir Crit Care Med 2000; 162: 1949-1956.

20 Matute-Bello G, Wurfel MM, Lee JS, et al. Essential role of MMP-12 in Fas-induced lung fibrosis. Am J Respir Cell Mol Biol 2007; 37: 210-221.

21 Kanazawa H, Tochino Y, Asai K. Angiopoietin-2 as a contributing factor of exercise-induced bronchoconstriction in asthmatic patients receiving inhaled corticosteroid therapy. J Allergy Clin Immunol 2008; 121: 390-395.

22 Roberts JR, Perkins GD, Fujisawa T, et al. Vascular endothelial growth factor promotes physical wound repair and is anti-apoptotic in primary distal lung epithelial and A549 cells. Crit Care Med 2007; 35: 2164-2170.

23 Voelkel NF, Vandivier RW, Tuder RM. Vascular endothelial growth factor in the lung. Am J Physiol Lung Cell Mol Physiol 2006; 290: L209-L221.

24 Demedts M, Behr J, Buhl R, et al. High-dose acetylcysteine in idiopathic pulmonary fibrosis. N Engl J Med 2005; 353: 2229-2242.

25 Lemjabbar $\mathrm{H}$, Gosset $\mathrm{P}$, Lechapt-Zalcman, et al. Overexpression of alveolar macrophage gelatinase $B$ (MMP-9) in patients with idiopathic pulmonary fibrosis: effects of steroid and immunosuppressive treatment. Am J Respir Cell Mol Biol 1999; 20: 903-913. 